$101-119$

\title{
EL EROTISMO COMO CONSUMO CULTURAL QUE EVIDENCIA VIOLENCIA SIMBÓLICA
}

\section{THE EROTIC EVIDENCE AS CULTURAL CONSUMPTION SYMBOLIC VIOLENCE}

Carolina Serrano-Barquín Patricia Zarza-Delgado

\section{Resumen}

Los deseos, placeres y emociones que se relacionan con la sexualidad y erotización femenina han sido reprimidos como una expresión del poder masculino. Bajo esta perspectiva, en este trabajo se presentan algunos resultados de una investigación en la que se entrevistaron a estudiantes universitarios de la ciudad de Toluca, se aprecia que al hablar de sexualidad se refieren específicamente a aspectos corporales y que sus experiencias son muy diferentes e inequitativas entre hombres y mujeres. Los jóvenes suelen vincular la sexualidad con conceptos tales como reproducción, calidez, amor y placer. Asimismo, el tema refleja ciertas connotaciones de moralidad e inmoralidad, pecado y peligro y la imposición de relaciones de poder, dominación y otros estereotipos. Así pues, a partir de las entrevistas y de consumos culturales se percibe que la sexualidad y el erotismo involucran también violencia simbólica.

Palabras clave: sexualidad, represión, discriminación de género

\section{Abstract}

The desires, pleasures and emotions that relate to female sexuality and eroticism have been repressed as an expression of male power. Under this perspective, this paper presents some results of an investigation in which college students were interviewed in the city of Toluca, is seen discussing sexuality that 
specifically address physical aspects and their experiences are very different and inequitable between men and women. Young people often link sexuality with concepts such as reproduction, intimacy, warmth, love and pleasure. Also, the theme reflects certain connotations of morality and immorality, sin and danger, as well as imposition of power relations, domination and other stereotypes. Thus, from the interviews and cultural consumption is perceived sexuality and erotic also involves symbolic violence.

Key Words: sexuality, repression, gender discrimination

\section{INTRODUCCIÓN}

La construcción de ideas y valoraciones de género en nuestra sociedad, se encuentran inmersas en escenarios históricos con complejas relaciones de poder cuya principal característica probablemente es, según lo afirma Bourdieu (2003), que no siempre se imponen con la evidencia de la obviedad debido a su carácter simbólico. Es decir que, debido al adoctrinamiento o ideologización que han recibido por diversos medios, las mismas mujeres aplican a cualquier realidad y, en especial, a las relaciones de poder en las que están atrapadas, unos esquemas mentales que son el producto de la asimilación de estas relaciones de poder que reflejan lo que el autor denomina la violencia simbólica, violencia amortiguada, insensible, e invisible para sus propias víctimas, que se ejerce esencialmente a través de los caminos puramente simbólicos de la comunicación y del conocimiento.

Así como existe la violencia simbólica, existe el intercambio simbólico de objetos, poder y afectos es una forma de interacción de la sociedad, "En el intercambio subsisten dos lógicas principalmente que se estorban mutuamente: una lógica fantasmática, que se refiere principalmente al psicoanálisis, sus identificaciones, proyecciones y todo el reino imaginario de la trascendencia, el poder y la sexualidad que actúan en el nivel de los objetos y el entorno, con un privilegio concedido al eje casa/automóvil (inmanencia/trascendencia); y una lógica social diferencia/que efectúa distinciones refiriéndose a una sociología, ella misma derivada de la antropología (el consumo como la producción de signos, diferenciación, posición social y prestigio). Detrás de éstas lógicas, en cierto modo descriptivas y analíticas, estaba ya el sueño de intercambio simbólico, un sueño de la condición del objeto y el consumo más allá del intercambio y el uso, más allá del valor y la equivalencia. En otras palabras una lógica sacrificia/de consumo, regalo, gasto, grandes convites y - la parte maldita- " (Baudrillard 1988, 187). Este intercambio de objetos, poder y afectos consolida la inequidad de género.

Desde una perspectiva psicoanalítica la simbolización hace referencia a procesos psíquicos que tienen un pasado particular, según Silvia Blechmer (2009), en un sentido clásico: "Un símbolo solo puede pensarse desde a partir de una regla que permite la interpretación de un representamen, de un elemento de la realidad que hace signo" (p.345), y en una interpretación al estilo perciano el representamen es la parte sígnica más abstracta, es la parte emotiva o cualia.

Por lo antes mencionado el presente artículo se integra de las siguientes partes: Erotismo, cuerpo y violencia simbólica. Los consumos culturales y el imaginario social de los mercados y finalmente algunas reflexiones en torno a los resultados de investigación.

\section{EROTISMO, CUERPO Y VIOLENCIA SIMBÓLICA}

Desde una perspectiva estética, es posible que el cuerpo erotizado motive la creación, es decir, se relaciona con el fogoso Eros, según Serrano, Zarza y Serrano (2012) el cuerpo erotizado de la persona creativa seduce y cautiva convocando al otro que también podría estar erotizado/hechizado al compartir el objeto deseado. En esta relación hay placer del momento incierto, de la experiencia sensual que provoca este vínculo. El erotismo no es visible, no es epidérmico, es sensación pura.

El erotismo para Morin (2003) es la relación entre la mente y el sexo, desborda las partes genitales, se apodera del cuerpo que deviene todo entero excitante, perturbador, apetitoso, emocionante, provocador, exaltador, y puede sublimar aquello que, fuera de la lubricidad, parece inmundo. De tal suerte que el Eros, "que nunca ha conocido ley", transgrede reglas, convenciones, prohibiciones. La mente perturbada por el sexo y perturbándolo (en la cabezaa-cola psique-falo) se erotiza. El Eros va a proyectarse y expandirse por todas partes, incluidos los éxtasis religiosos; va a extraviarse en los fetichismos. La atracción erótica deviene fuente de complejidad humana, desencadenando encuentros improbables entre clases, razas, enemigos, amos y esclavos. "El eros irriga mil redes subterráneas presentes e invisibles en cualquier sociedad, 
suscita miradas de fantasmas que se levantan en cada mente. Opera la simbiosis entre la llamada del sexo, que procede de las profundidades de la especie, y la llamada del alma que busca adorar" (Morin, 2003, p. 45).

Particularmente, el arte erótico según Döpp (2006), se encuentra sumido en una enrarecida atmósfera de términos ambiguos. "El arte y la pornografía, la sexualidad y la sensualidad, la obscenidad y la moralidad están relacionados hasta tal punto que parece casi imposible llegar a una definición objetiva, lo cual es muy común en la historia del arte..." (p.19). Ya que la pornografía es un término moralizador difamatorio. Lo que para una persona es arte, para otra es un trabajo diabólico. La mezcla entre aspectos estéticos y ético-moralistas impide la aclaración o diferenciación entre ambos términos. Asimismo, refiere el término pornografía, que en griego significa "escritos de prostitutas" (o sea, un texto con contenido sexual), por tanto la pornografía estaría construida por las fantasías sexuales y las fantasías eróticas serían el tema del arte erótico, de tal suerte que podría ser el erotismo es una condición psíquica.

Si la belleza se encuentra en la mirada del observador, el erotismo se encuentra en su mente. Lo que gobierna nuestras reacciones, no es únicamente lo que miramos o leemos, sino la forma en que lo percibimos. La imagen o el texto pueden estimular, ofender o provocar ambas cosas de manera simultánea. Por lo menos desde el siglo XIX a la fecha, la cultura occidental muestra una larga historia de atentados oficiales por suprimir el erotismo (Lucie-Smith, 2003), generando formas de censura y satanización del cuerpo como en la Santa Inquisición. La mera actividad sexual es diferente del erotismo, para Bataille (2000), la primera se da en la vida animal y es tan sólo en la vida humana que se muestra una actividad que determina lo que denominamos erotismo. Humanamente, la unión de amantes o esposos sólo tuvo un sentido, el deseo erótico: el erotismo difiere del impulso sexual animal en que es, en principio, de la misma forma que el trabajo, la búsqueda consciente de un fin que es la voluptuosidad. Es cierto, la búsqueda del placer, considerado como un fin en nuestros días, es a menudo mal juzgada. En una reacción primitiva, que no cesa de operar del todo hoy día, la voluptuosidad es el resultado previsto del juego erótico. Así pues, el resultado del erotismo es considerado en la perspectiva del deseo, independientemente del posible nacimiento de un hijo.

La cultura occidental traída del viejo mundo hacia América, incluía un modelo de mujer que consagra la pureza prenupcial, la fidelidad al marido, la devoción a los hijos, la laboriosidad doméstica, resaltando con ello las virtudes de lealtad, prudencia, castidad, sumisión, recato, abnegación y espíritu de sacrificio, principalmente. Pero, no todas las mujeres encajaban en este modelo, estaban siempre al acecho las criaturas "malignas y seductoras", mientras que en el extremo opuesto, aguardaban literalmente, las santas. Una combinación de estos estereotipos se encuentra en las mujeres mexicanas como la Malinche; concubina, madre, compañera y en la de muchos casos, "la otra", la pecadora. Rosario Castellanos (1992), comenta que para la mujer bastaba un buen funcionamiento de las hormonas, una resistencia física suficiente y una salud que serían los otros dones para transmitirlos por generaciones, pero cuando surgió un genio como sor Juana Inés de la Cruz, no había forma ni de clasificarla ni de asimilarla socialmente, como tampoco de colocarla con certeza dentro del imaginario femenino o el masculino ya que pudo ser predecesora de la emancipación femenina desde la mirada del otro (Serrano y Zarza, 2012). ${ }^{1}$

Esta concepción de lo femenino contrasta con la de las culturas prehispánicas "El concepto femenino que tenían los hombres que arribaron al Nuevo Mundo giró en torno a esa tradición cultural (...), la dicotomía erótica entre el bien y el mal" (Barbosa, 1994, p. 79). Evidentemente, en el imaginario masculino de dominación surgieron dos míticos personajes femeninos: una, la voluptuosa, seductora y ninfómana, o la otra; la casta, fiel y sumisa virgen que sólo sirve para la procreación, mientras que el imaginario de lo femenino está plagado de historias que demuestran la peligrosidad de ese animal incontenible que ha representado la mujer, ya sea demoníaca o virtuosa, a lo largo de la historia y que, según esta tradición, a las mujeres hay que encerrarlas, esconderlas, atosigar con prejuicios, ascos y pudores; extrañarlas de sus cuerpos, ya que sólo así "puede construirse un mundo existible donde no prive la omnipresente amenaza de la indomable y ardiente sexualidad femenina. Y sin embargo (...), la figura de la ninfómana florece para desquitarse del horror con que se quiso desterrar la sensualidad de nuestro opresivo universo" (Moreno, en Serrano y Serrano, 2008, p. 43), de esta manera se fundamenta la dicotomía de la mujer como mito.

Esta sensualidad reprimida en las mujeres durante tanto tiempo ha tenido que salir y con la liberación femenina que pretende reconocer las sensaciones placenteras, las prácticas sexuales y la expresión de las emociones, afectos y deseos de las mujeres en este estado de seducción que no era permitido

${ }^{1}$ En este apartado se retoma parte del capítulo denominado "Sexualidad, sensualidad y erotización inequitativa" del libro Genero y desigualdades en lberoamérica, de Vélez y Baca (comp.) 2012 por la editorial autores en el Primer Congreso Internacional: Mujeres, Literatura y Arte. Benemérita Universidad Autónoma de Puebla. 
empieza a reconocerse. Si bien, la sensualidad está muy ligada a la seducción, no necesariamente implica una práctica sexual. La sexualidad no obedece ni es la manifestación de un impulso biológico y natural, tampoco se restringe a formas universales y generalizables de expresión (Rivas, 1998). Por el contrario, se le entiende como un entramado diverso y particular de prácticas, acciones, técnicas, placeres y deseos en los que interviene el cuerpo, pero también una serie de argumentaciones, discursos, premisas y significaciones que connotan las acciones de los individuos, califican sus deseos, orientan sus tendencias y restringen sus elecciones de pareja.

Desafortunadamente, las actuales representaciones del cuerpo aterrizan en la objetualidad: usar, desechar, renovar, remodelar. Los medios fomentan un culto actual al cuerpo que lo aterriza en la concepción de ser mercancía y moneda de cambio. Los medios han inducido la idea que el ser "más" mujer va en relación directa con el tamaño de los senos y el ser "mas" hombre con el tamaño del pene. Lo que apunta a la exagerada estética de los cuerpos trabajados en el gimnasio e imposibles por naturaleza, al menos en nuestra cultura; razón por la que el recorte espacial en los planos de visualización en los medios apunta a una concepción de los individuos a partir de la remarcación de estos indicadores sexuales, una imagen indicial. "La mirada... es obscena por su inmediatez,...son fragmentados y convertidos en fetiches para servir de alimento a la voracidad escópica masculina" (Gimenez Gatto, 2008, p.100). Maximizando la sexualidad y minimizando la sensualidad y el erotismo.

Ya no se contempla al cuerpo en su totalidad, sino a partir de lo fragmentario, las mujeres son grandes senos, los hombres son penes y vientres marcados, tal es el caso de la imagen con tintes eróticos y sexuales, lo cual se opone en gran medida al planteamiento del "hombre de Vitruvio", aquel conceptuado desde la totalidad mas allá incluso de sus propios límites, es decir, una totalidad que lo hacía extensible incluso a una relación directa con el universo, a un nivel superior al mero plano de representación. "Un lenguaje de la proximidad, una obsesión por la visibilidad del sexo que se expresa, a nivel formal, en el plano cerrado y en sus sinónimos porno, una mirada genital y clínica del sexo... una mirada fragmentaria y fálica sobre unos cuerpos sin rostro, objetivados y reducidos a la carnalidad..." (Gimenez Gatto, 2008, p. 97). Es quizá la exposición de esos fragmentos corporales los que provocan a la gente joven.

Históricamente las religiones han impuesto censura a la visibilidad del cuerpo y más aun, a la posibilidad de erotizarlo; en el caso de la religión católica (la que domina en Latinoamérica), la tecnología del pecado denominada así por Michel Foucault (2001), resume los esfuerzos de una sociedad para ejercer el control social de los cuerpos, en particular de aquellos que pueden cumplir la función reproductora de la colectividad otorgando cargas y sentimientos de culpa a quienes ejecutan prácticas sexuales sin la aprobación general. En lo individual, la disponibilidad de los cuerpos femeninos se ejerce desde las jerarquías del poder; en el ámbito privado, el pater familias ha sido quien elige las formas de practicar dichas relaciones para las integrantes del claustro familiar.

Por otra parte, el cuerpo humano, desde los estudios de género es el producto resultante de un conjunto de construcciones culturales tanto desde el imaginario social como desde el individual, pues no se circunscribe a su dimensión física o biológica; por lo tanto, el cuerpo es parte de una realidad fáctica y está delimitado a su corporeidad. El cuerpo también se concibe desde su dimensión simbólica y por ello es portador de múltiples significados, que resultarán cambiantes y móviles constantemente, en tanto no son una constante en el tiempo, sino que éstos se enlazan a un particular momento socio-histórico; estos cuerpos socialmente construidos son un "efecto de la actividad cultural e histórica" (Fuente, 2009, p. 667). Asimismo, el cuerpo es también un reducto para las expresiones de esos controles del poder y la censura religiosa, o las formas de recato ${ }^{2}$, donde el consumo cultural de los cuerpos femeninos sensualizados promueven la fragmentación corporal que deviene en la violencia ejercida a la carnalidad, el deseo o cualquiera de las formas de erotizar la imagen del cuerpo femenino. Es también el modo mismo del ultraje a la carne y el ámbito donde la forma primordial de la unidad se pone en cuestión.

La desnudez del cuerpo, y su exhibición para la mirada masculina, ha sido considerada un aspecto que forma parte del proceso de erotización; esto queda demostrado desde la antigüedad con la filosofía y arte griegos, donde la idealización del cuerpo requería como su detonador la belleza corporal hecha canon: "Entre los griegos la belleza encierra virtud, y la virtud se expresa en la belleza. Se ha construido la imagen genérica del hombre perfecto. El desnudo se ha convertido en un vestido" (Sánchez, 2005, p. 22), donde belleza e ideal corporal se entienden en su unidad, en su integridad física y se excluye la fragmentación..."si el cuerpo se fragmenta, por las razones que sean, si las

2 Silvia Navarrete asegura que: "Hoy, a pesar de la diversidad cultural, de las vanguardias artísticas y de la contracultura de los años sesenta; a pesar de las herramientas modernas del conocimiento, llámese $159)$. 
figuras nacen de su propia carne, ¿por qué ésta se destruye y se disuelve?" (Barrios, 1998, p. 173), una respuesta podría ser en el sentido de que la imagen del cuerpo desnudo es superada por la fuerza del deseo o como resultado del ejercicio del poder; su fragmentación o acercamiento (zoom) a las zonas erógenas, para el caso de la fotografía y el vídeo, es más efímera aun y se disuelve en la medida en que el deseo se satisface.

La disponibilidad del cuerpo femenino tanto en las formas tradicionales de aparejamiento ${ }^{3}$ como mediante la oferta de la prostitución o la pornografía, deja ver la posesión del cuerpo femenino como una manifestación del poder económico, político o simplemente como ejercicio de la superioridad de fuerza o producto de las jerarquías sociales. En palabras de Sara Martín "el modelo femenino que se ofrece se basa en la viejísima idea de que la mujer acapara poder a través de la sexualidad" (Martín, 2005, p. 183), por lo que una de las primeras formas de empoderamiento de la mujer en tiempos antiguos, fue acercarse a los varones en el poder mediante sus posibilidades de erotizarlos.

El proceso de construcción de esa imagen parte de la visión masculina que la erige convirtiendo el cuerpo femenino en un producto, en un objeto dispuesto para ser contemplado y gozar en ello. El entramado con el que juegan los videos musicales, en este aspecto, es que el cuerpo femenino es atendido y tendido tanto por/para hombres como por/para mujeres. En el caso del sector masculino se puede apuntar a una especie de placer voyeurdonde el espectador puede sentirse como si estuviera en un pase privado y las imágenes estuviesen puestas y dispuestas sólo para él (Faciabén, 2009, p. 623).

Para las mujeres, en cambio, el cuerpo presentado adopta la categoría de discurso modélico de triunfo y éxito sin olvidar el hecho de que una mujer mire a otra mujer no está penado bajo condena de homosexualidad como sí sucede en el ámbito masculino. En esto la ley es clara: si ellas miran, son envidiosas; si lo hacen ellos son homosexuales. Por tanto y aunque pueda parecer una contradicción, la fuente de discurso es una y la misma para ambos sectores. En un caso porque el cuerpo femenino sirve de placer y ayuda a reforzar el andamiaje con el que se sustenta el bastidor cultural heterosexista que lo envuelve. Por otra parte, ese discurso se asienta, cuando ellas lo acogen y lo asumen en sus vidas y prácticas más cotidianas. Es mediante este proceso que la mujer somete a una mirada masculinizada el cuerpo femenino y la feminidad,

${ }^{3}$ Silvia Navarrete habla de modo determinista sobre la falta de permisividad social para las relaciones extramaritales: "La libertad de expresión es relativa y sólo se tolera, en lo que concier pa a las riación de una mujer que no puede dejar de ser victima" (Navarrete 1998,159$)$. convirtiéndolo igualmente en producto $y$, por tanto, (im)poniendo el mismo discurso del hombre-sujeto que toma el cuerpo femenino como un bien de consumo más (Faciabén, 2009, pp. 623-624). Otra vez el cuerpo y el erotismo como consumo cultural.

La integración del cuerpo física y emocionalmente permite la recuperación del ser humano en su totalidad, en su posibilidad erotizante y sensualizante. Como ya se mencionó, Vitruvio conceptualiza el cuerpo como una totalidad, aquello que va mas allá, incluso de sus propios límites, una totalidad que lo hace prolongable inclusive con una relación que lo conecta directamente al universo. Esto se explica con el siguiente gráfico.

\section{Figura 1: Triadicidad sígnica}

CUALISIGNO

Sensualidad; lo inefable (el cuerpo metaforizado)

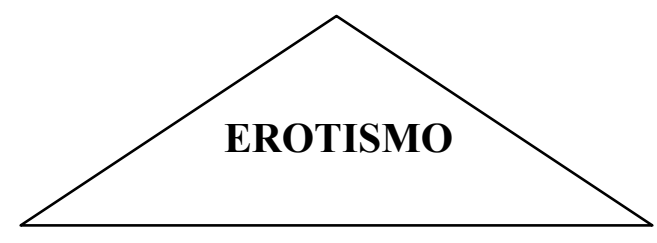

SINSIGNO

Cuerpo expresado a través del placer

o del sufrimiento. Cuerpo erotizado o

culpabilizado que puede ser motivo

de agresión y maltrato

LEGISIGNO

Género, construcción cultural

a través de representaciones

simbólicas que puede llevar a la

creación o destrucción

Fuente: Elaboración propia

\section{LOS CONSUMOS CULTURALES}

Y EL IMAGINARIO SOCIAL DE LOS MERCADOS

Los consumos culturales están íntimamente vinculados con los mercados oferentes-ofertantes. Se puede afirmar que el individuo contemporáneo requiere de una comunicación interactiva con los otros para fortalecer su propia 
identidad (Sitaram \& Codgell, citados en Páramo, 2012) y para el caso que nos ocupa para su identidad sexual. Por ello, resulta de singular importancia el papel de los consumos culturales -entre ellos el erotismo-que ofrecen los mercados, ya que se encuentran en un constante proceso de creación y re-creación de todo aquello que identifica y hace a los miembros de determinado grupo social a veces impredecibles, dinámicos e inestables. Así, los mercados son vistos como entes sociales en construcción desde el significado que se les concede a los objetos sometidos al intercambio (simbolización y de- simbolización), a las partes que intervienen (el imaginario social de los mercados) y a las normas con las que se rigen dichos intercambios (Spillman, 1999). Páramo (2012) afirma que en los mercados interactúan:

1. Construcción cultural de los objetos de intercambio. En ésta interviene un proceso de simbolización -legitimación social- el cual es muy diferente, dependiendo de la cultura que se trate y corresponde a la ideología, valores, creencias y supuestos culturales dominantes. De tal suerte, que muchos productos u objetos que en el pasado eran casi una profanación comercializarlos hoy son parte de los satisfactores que se ofrecen en el mercado de forma muy atractiva y competitiva. Resulta muy peligroso si no se comprenden suficientemente los vínculos entre lo que representan estos productos para la cultura en la que se quieren comercializar y la simbología con la que se les quiere asociar. Esta no siempre bien comprendida simbolización, que podría ser denominada simplemente culturización, ha sido la causa más representativa de aquellas organizaciones exitosas que han sido capaces de despojarse del tradicionalismo economicista de analizar el significado de productos para adquirir sensibilidad antropológica $y$, con ello, poder dimensionar el fenómeno de consumo en sus justas proporciones. Por ello, se ha propuesto el etnomarketing (Páramo, 2005) como una forma de abordar tal complejidad.

2. Construcción cultural de las partes del intercambio. El intercambio de significados es una construcción social de las partes que participan en el imaginario social del mercado. Ello para hacer referencia a que al contrario de lo que se creía, las transacciones comerciales no se hacen aisladamente con individuos sino con grupos (organizaciones, naciones, familias...) o, al menos, con personas que representan a un grupo específico. Lo más importante, es el rango asignado al imaginario social del otro como potencial contraparte de la transacción en el mercado. Esta contraparte puede ser, implícita o explícitamente, delimitada por aspectos geográficos, demográficos, étnicos, raciales, de género, de nación, de redes sociales existentes y de clase social, entre otros. En cuanto a las clases sociales, sea tal vez la categoría que más se utiliza en marketing para que a través de la denominada movilidad social se busquen productos que simbólicamente los van a hacer ver mejor, casi como haciendo parte de una clase social más alta y de mayor refinamiento. Aquello que Veblen (1899) denominó el consumo conspicuo o de emulación. Estos simbolismos estrechamente atados al grado de aceptación y de poder.

3. Construcción cultural de las normas del intercambio. Esta construcción se refiere a la interpretación que se hace de las normas que son llevadas al mercado, así como a las formas a través de las cuales, formal o informalmente, se juzga o se sanciona en él. Los intercambios en un mercado se caracterizan por la competencia entre compradores y entre vendedores, correspondiéndoles a los agentes de ese mercado interpretar y evaluar las transacciones realizadas al amparo de tales reglas. Páramo (2012) concluye diciendo que hay que develar desde la antropología, los aspectos ocultos del comportamiento de todos los agentes del mercado involucrados: desde la demanda (consumidores, compradores, clientes), desde la oferta (organizaciones sociales, empresas competidoras), desde la intermediación (canales de distribución, agentes), desde la regulación (instituciones estatales y gubernamentales), adquiriendo así un entrenamiento etnográfico que permita estudiar, analizar y sobre todo comprender, las complejidades propias de los mercados contemporáneos, en los que los valores, las creencias y el mundo subyacente son los que pueden dar cuenta de los comportamientos y los artefactos (Schein, 1985) que circulan en los mercados contemporáneos. 


\section{Figura 2: Triángulo semiótico}

SINTÁCTICO

\section{CONSTRUCCIÓN CULTURAL DE LOS OBJETOS DE INTERCAMBIO}

Significados que se les otorgan a los objetos sometidos a intercambio a través de una simbolización

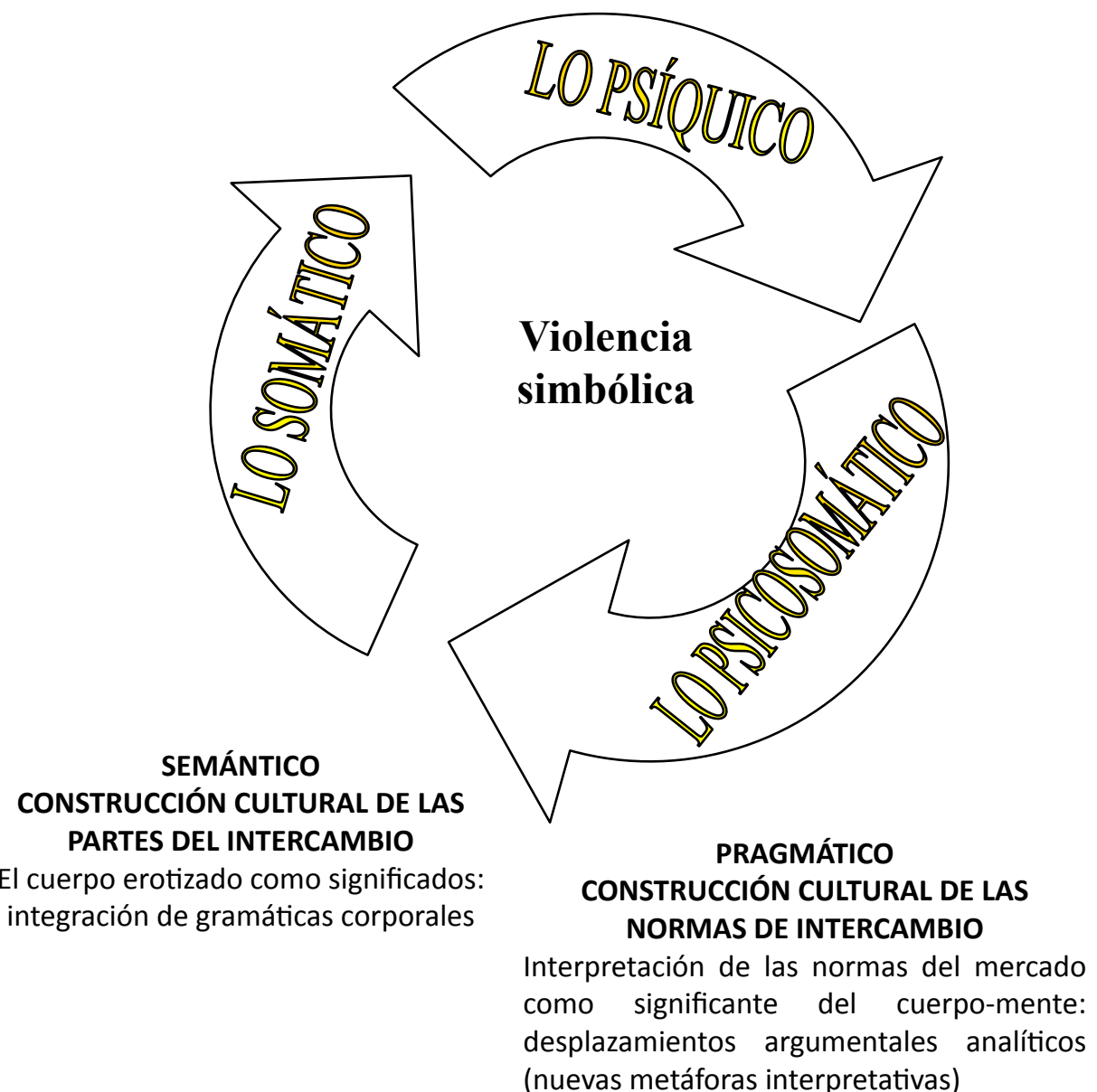

Fuente: elaboración propia

\section{REFLEXIONES EN TORNO A LOS RESULTADOS DE INVESTIGACIÓN}

La elección de la primera pareja sexual puede definir la sensualidad y el erotismo que más tarde manifestará la mujer a lo largo de su vida sexual. A continuación se presentan algunos comentarios de los universitarios entrevistados que marcan su iniciación sexual. Se aprecia también en los resultados de este estudio que las mujeres participantes constantemente parecen establecer vínculos entre amor y relaciones sexuales, a veces incluso sobrevalorando o idealizando una relación sexual que surge del amor, al grado de llegar a pensarlo como un objetivo primordial de la vida tal como lo señala una de ellas quien comenta que una vez que se han tenido relaciones sexuales con el joven a quien se ama "ya se puede morir en paz".

De esta manera, el tema de la iniciación sexual entre las jóvenes del estudio refleja ciertas connotaciones de moralidad e inmoralidad que se ven matizadas o justificadas cuando existe un lazo amoroso hacia la otra persona y cuando surge de manera espontánea, es decir no planeada, así lo sugiere otra de ellas cuando comenta "mi primera relación sexual fue con mi novio... fue en su casa, no lo sugirió alguien sino que fue poco a poco hasta que se dio, como le tenía mucha confianza y cariño, pues estuvo bien, o sea así sin miedo ni remordimientos". En este sentido, pareciera que la sexualidad femenina no debe regirse por la planeación o el proyecto, sino ser motivo de afecto y emociones. Si acontece como asunto de la naturaleza, en el sentido de la creación de Dios o de la efervescencia de los impulsos naturales, queda eximida de premeditación y por tanto de indignidad. Bajo esta perspectiva, una sexualidad planeada por las mujeres sería percibida como algo indebido e inmoral.

Otro aspecto sobresaliente y diferenciado en la primera experiencia sexual entre los varones y mujeres de este estudio, se relaciona con un ideal sexual activo en ellos y pasivo en ellas, lo cual refleja ciertas concepciones tradicionales según el esquema predominante culturalmente. Por ejemplo, en términos generales, las jóvenes participantes señalan que ellas no sabían qué hacer en ese primer encuentro sexual y fueron ellos quienes lo propusieron, las guiaron y, de alguna manera, les enseñaron lo que tenían que hacer, son agentes pasivos que despiertan a la vida sexual gracias al hombre.

La mujer tiene hoy día un papel más activo, que de alguna manera refleja menor desigualdad genérica que en el pasado, pero sobre todo, mayor información. Bajo esta perspectiva, las jóvenes participantes ciertamente 
parecen mostrar una mayor información y con ello mayor responsabilidad y conciencia de su sexualidad, sobre todo de los riesgos y consecuencias que una vida sexual activa conllevan, tales como embarazos y enfermedades. Así se percibe cuando las jóvenes comentan sobre los múltiples métodos de anticoncepción que conocen y emplean, tales como la píldora de emergencia, las píldoras anticonceptivas, los dispositivos intrauterinos, los dispositivos intramusculares y los parches anticonceptivos. De tal suerte que la sexualidad y el erotismo, ya no implica solo la reproducción, es un asunto de elección.

Aparentemente la iniciación sexual de los y las jóvenes participantes es un ámbito claro de relaciones de poder entre el varón y la mujer en donde él lleva el rol activo y dominante y ella el rol pasivo y sumiso. $Y$ a pesar de que pareciera que las mujeres ejercen más libremente su sexualidad al emplear diversos métodos anticonceptivos que principalmente disminuyen las preocupaciones que ellas pudieran tener por un embarazo no deseado, tal parece que, a diferencia de los hombres, se sienten fuertemente comprometidas en una relación de pareja una vez que se han tenido relaciones sexuales. Esta situación sin lugar a dudas la ubica en una posición de desigualdad frente al varón y probablemente tiene su origen justamente en la interiorización de ciertas prescripciones sociales que sobre la virginidad femenina se tenían en el pasado y que en algunos casos todavía son fuertemente solicitadas e incluso motivo de violencia de género.

Particularmente en lo relacionado a la diferenciación de género, Weeks (1998) señala que la masculinidad y la feminidad son, en gran medida, definidos en referencia a la elección del sujeto con quien se tendrá actividad sexual. Ser un hombre es tener sexo con una mujer y viceversa. En esto radica, en parte, la importancia de estudiar la sexualidad como una dimensión de la identidad de género que además, según lo refiere Lamas (2000), es construida discursivamente, regulada y reglamentada mediante prohibiciones y sanciones que le dan -literalmente- forma y direccionalidad. La sexualidad está sujeta a una construcción social y es muy sensible a la cultura, a las transformaciones sociales, a los discursos y a las modas. Asimismo la sensualidad y la erotización femenina están expuestas a procesos complejos de aceptación o censura cultural.

En este sentido, se presume que el estudio de los jóvenes a partir de la manera en que construyen o conciben la sexualidad, permitirá identificar las posibles desigualdades de género o bien las transformaciones sociales que en este aspecto lleguen a reflejarse hasta en las conductas más sutiles y tenues, a veces apenas perceptibles, de los diferentes ámbitos de la sexualidad en los y las jóvenes universitarios.

Por otro lado, en los comentarios que los y las jóvenes entrevistados hacen sobre la sexualidad femenina y masculina, surgen otras diferencias de percepción entre varones y mujeres al expresar lo que consideran más placentero de las relaciones sexuales. Sobre este tema los varones del estudio hacen referencias a sensaciones primordialmente físicas que van desde los besos, los abrazos y las caricias, hasta el orgasmo. En el lado opuesto parecen ubicarse las mujeres entrevistadas, quienes al hablar de lo que ellas consideran más placentero de las relaciones sexuales, suelen mencionar algunos aspectos más relacionados con emociones o sentimientos. Por ejemplo Delia comenta al respecto "lo más placentero para mi es el sentimiento y con eso te das cuenta por qué están pasando las cosas...o sea por amor... y eso es lo que yo siento que te hace sentir más o menos." Las mujeres del estudio también hacen referencias reiteradas a que lo más placentero de las relaciones sexuales es percibir la "emoción" o "satisfacción" que ellas pueden provocar en ellos.

Lo anterior de alguna manera evidencia que no parece haber entre las mujeres participantes una clara conciencia y aceptación de la sensualidad y disfrute sexual. Por ejemplo no hubo alguna de las jóvenes que mencionara el orgasmo como lo más placentero de las relaciones sexuales, lo que hace pensar que sigue existiendo, en este aspecto, una cierta polaridad entre lo masculino y lo femenino. En este sentido, Rivas (1998) señala en su estudio comparativo entre abuelas, madres e hijas, que las mujeres más jóvenes muestran mayor aceptación de la sensualidad y naturalidad biológica del organismo, mientras que las abuelas y las madres siguen reflejando una cierta negación del deseo, el impulso sexual, las caricias y en general la sensualidad femenina porque lo asocian al ámbito de lo prohibido, de la prostitución, la infidelidad y la indecencia. En comparación con los hallazgos de Rivas, las jóvenes participantes en esta investigación, parecen tener una postura más cercana a la de las abuelas y las madres ya que no existe algún comentario en el que ellas muestren un interés específico por complacer su sensualidad. Por lo que se puede afirmar que, el discurso amoroso enmascara la verdad de la especie: la novela y la propaganda mediática, como la publicidad y el cine, la televisión y la prensa llamada femenina, giran alrededor del flechazo, la pasión, el formidable poder del sentimiento, del amor con mayúsculas, "el deseo representa una energía peligrosa para el orden establecido...la codificación ascética de los deseos y placeres: la voluntad salvaje de reducir a la nada la increíble potencia de lo femenino" (Onfray, 2008: 124), todavía prevalece. 
Según Welti (2001), esta situación muestra una cierta represión femenina que refleja una relación de desigualdad en el ámbito de lo íntimo, que controla el placer femenino y con ello el poder sigue siendo ejercido por el hombre. Según el autor, probablemente la eficacia de esta forma de ejercer el poder masculino radica en el hecho de que aquella mujer que se atreve a manifestar una posición distinta en cuanto a complacer su sensualidad, asume los riesgos de ser marginada de ciertos roles que todavía está interesada en representar como sería el de cónyuge.

Amuchástegui (1998) también señala que entre varones y mujeres se espera que el deseo y el erotismo lo tengan los hombres, casi como un elemento necesario para la afirmación de su identidad de género. Por el contrario, si es una mujer quien demuestra maestría y habilidad en este aspecto durante el coito, es inmediatamente considerada como "experimentada", lo que significa que ha tenido más de un compañero sexual y que, por tanto, tiene una reputación sexual dudosa y por tanto no sería merecedora de matrimonio y de vida familiar. Para esta autora, la necesidad de control de la sexualidad femenina en diferentes sociedades y culturas a través de la historia ha sido considerada como una de las expresiones más importantes de la desigualdad de género que, por lo que se percibe en el presente estudio, se mantiene vigente por lo menos entre el grupo de los y las jóvenes universitarios entrevistados.

Pareciera que la sensualidad y la erotización están en proceso de extinción y solo se da importancia a la expresión sexual. Se puede inferir que para los jóvenes universitarios encuestados las diferencias entre sexualidad, sensualidad y erotismo no son muy claros y por sus comentarios tienen una percepción aproximada de estos aspectos pero los relacionan exclusivamente con la práctica sexual. El cuerpo se ha vuelto otra mercancía más, que como menciona Bauman, como otras mercancías del mercado, son productos concebidos para ser consumidos instantáneamente, en el acto y por única vez. Es decir, evadir los compromisos y actuar con inmediatez "Que la gente conserve la ropa de ayer, así como la computadora, el teléfono móvil o los cosméticos podría significar el desastre para una economía cuyo mayor interés, y también la condición sine qua non de su supervivencia, es que los productos vendidos y comprados vayan a la basura con rapidez y sin dilación; y en este aspecto de la economía el saber qué hacer con lo que no sirve es en sí una industria de máxima calidad" (Bauman, 2007: 146). Pareciera que solamente la sexualidad inmediata es lo que importa, es decir, el consumo corporal.

\section{BIBLIOGRAFÍA}

- Amuchástegui, Ana (1998). "Saber o no saber sobre sexo: los dilemas de la actividad sexual femenina para jóvenes mexicanos", en Szasz y Lerner (coord.) Sexualidades en México. Algunas aproximaciones desde la perspectiva de las ciencias sociales. México: El Colegio de México.

- Barbosa, Araceli (1994). Sexo y conquista, México: CDEL-UNAM.

- Barrios, José Luís (1998). "El Cuerpo Fragmentado", en El cuerpo Aludido. Anatomías y construcciones. México: CONACULTA-INBA.

- Bataille, George (2000). Las lágrimas de Eros. Barcelona: Tusquets.

- Baudrillard, Jean (2001). De la seducción. Madrid: Cátedra.

- Bauman, Zygmunt (2007). Tiempos líquidos. Vivir en una época de incertidumbre. México: Tusquets.

- Bleichmar, Silvia (2009). Inteligencia y simbolización; una perspectiva psicoanalítica. Buenos Aires: Paidós.

- Castellanos, Rosario (1992). Mujer que sabe latín, México: Fondo Cultura Económica.

- Döpp, H-J. (2006). Arte erótico. Bogotá: Panamericana Editorial.

- Faciabén, Jésica (2009). "La danza de los cuerpos en el siglo XXI: a propósito de las transgresiones lésbicas en el videoclip", en IV Congreso Internacional Ciencias, Humanidades y Artes: El Cuerpo Descifrad. Puebla: Universidad Autónoma Benemérita de Puebla.

- Foucault, Michel (2001). Historia de la sexualidad. Vol. I. México: Siglo XXI.

- Fuente, Eduardo de la (2009). "El cuerpo fragmentado y la psicosis social." en IV Congreso Internacional de Ciencias, Artes y Humanidades: El Cuerpo Descifrado. Puebla: Universidad Autónoma Benemérita de PueblaUniversidad Autónoma Metropolitana.

- Giménez Gatto, F. (2008). "Pospornografía” en Estudios visuales, núm. 5. Disponible en <http://www.estudiosvisuales.net/revista/pdf/num5/ gimenez gatto.pdf $>$ [15 de noviembre de 2011]

- Lagarde, Marcela (1990). Los cautiverios de las mujeres: madresposas, monjas, putas, presas y locas. México: Universidad Nacional Autónoma de México.

- Lamas, Marta (2000). El género: la construcción cultural de la diferencia sexual. México: Taurus.

- Lucie-Smith, E. (2003). Erótica. The Fine Artrs of Sex. USA: Hydra.

- Martín, Sara (2005). “El cuerpo en el videoclip musical: más que carne 
fresca" en Torras, M. (ed.) Corporizar e/ pensamiento: escrituras y lecturas. Pontevedra: Mirabel.

- Moreno, Hortencia (2004). "Ninfómanas y vírgenes", en Nexos, 26 (313), 19-28.

- Morin, Edgar (2003). El método; la humanidad de la humanidad. Madrid: Cátedra.

- Navarrete, Silvia (1998). "El cuerpo erotizado: desnudo y pudor en el arte mexicano", en Issa Benítez y Karen Cordero, El cuerpo aludido. México: MUNAL-CONACULTA.

- Onfray, Michel (2008). La fuerza de existir. Manifiesto hedonista. Barcelona: Anagrama

- Páramo Morales, Dagoberto (2012). “El mercado, una construcción cultural” en Pensamiento \& Gestión, núm. 33, julio-diciembre, 2012, pp. VII-XI

- Rivas, Marta (1998). "Valores, creencias y significaciones de la sexualidad femenina. Una reflexión indispensable para la comprensión de las prácticas sexuales" en Sexualidades en México. Algunas aproximaciones desde la perspectiva de las ciencias sociales. México: El Colegio de México.

- Sánchez, Carmen (2005). Arte y erotismo en el mundo clásico. Madrid: Ciruela.

- Serrano Barquín, Carolina y Patricia Zarza Delgado (2012). "Sexualidad, sensualidad y erotización inequitativa" en Vélez y Baca (comps.) Género y desigualdades en Iberoamérica, Buenos Aires, Argentina: Mnemosyne.

- Serrano Barquín, Carolina, Serrano Barquín, Héctor y Patricia Zarza Delgado (2012). "El cuerpo erotizado en la escultura" en Memorias del Primer Congreso Internacional: Mujeres, Literatura y Arte. Puebla: Benemérita Universidad Autónoma de Puebla.

- Serrano, Héctor y Carolina Serrano (2008). "La educación de género y su evidencia en la imagen fotográfica” en Espacios Públicos, 11(23), 265-278.

- Weeks, Jeffrey (1998). La construcción cultural de las sexualidades. ¿Qué queremos decir cuando hablamos de cuerpo y sexualidad? en Sexualidades en México. Algunas aproximaciones desde la perspectiva de las ciencias sociales. México: El Colegio de México.

- Welti, Carlos (2001). iQuiero contigo! Las generaciones de jóvenes y el sexo. Nuevas miradas sobre los jóvenes. México: Instituto Mexicano de la Juventud.
Carolina Serrano Barquín

Odontóloga, diplomada en: Docencia, Sexualidad, Educación abierta y a distancia y en Pensamiento creativo. Maestra en Planeación y evaluación de educación superior. Doctora en Ciencias Sociales. Docente en todos los niveles educativos principalmente en áreas artísticas, de creatividad y educación. Directora de educación a distancia Universidad Autónoma del Estado de México y Coordinadora de Educación abierta y a distancia de la Región Centro-sur de la Asociación Nacional de Universidades e Instituciones de Educación Superior. Diversas publicaciones, coautora libros: Creatividad sensorial. Cultura visual de género... Miembro del SNI. Profesora-investigadora de la Facultad de Ciencias de la Conducta, UAEMex,

Patricia Zarza Delgado

Diseñadora industrial con Maestría en diseño de productos en la Universidad Politécnica de Cataluña en Barcelona, España. Con una segunda maestría en Ciencias del Diseño en la Universidad del Estado de Arizona en los E.U.A. Doctora en Ciencias Sociales por El Colegio Mexiquense. Sus trabajos de investigación abordan temas relacionados con el diseño, la cultura de género y los bienes de consumo cultural. Ha publicado diversos artículos especializados en revistas nacionales e internacionales. Es miembro del Sistema Nacional de Investigadores. Profesora-investigadora de Facultad de Arquitectura y Diseño de la UAEMex. 